\title{
Growth, nutritional quality, and energy use efficiency in two lettuce cultivars as influenced by white plus red versus red plus blue LEDs
}

\author{
Zhengnan Yan ${ }^{1}$, Dongxian $\mathrm{He}^{1 *}$, Genhua Niu², Qing Zhou' ${ }^{1}$, Yinghua Qu ${ }^{1}$ \\ (1. Key Laboratory of Agricultural Engineering in Structure and Environment of Ministry of Agriculture and Rural Affairs, \\ China Agricultural University, Beijing 100083, China; \\ 2. Texas A\&M AgriLife Research Center at Dallas, Texas A\&M University System, Dallas, TX 75252, USA)
}

\begin{abstract}
Red plus blue light-emitting diodes (LEDs) are commonly applied in plant factories with artificial lighting due to photosynthetic pigments, which absorb strongly in red and blue light regions of the spectrum. However, plants grown under natural environment are used to utilizing broad-wide spectrum by long-term evolution. In order to examine the effects of addition light added in red plus blue LEDs or white LEDs, green and purple leaf lettuces (Lactuca sativa L. cv. Lvdie and Ziya) were hydroponically cultivated for 20 days under white LEDs, white plus red LEDs, red plus blue LEDs, and red plus blue LEDs supplemented with ultraviolet, green or far-red light, respectively. The results indicated that the addition of far-red light in red plus blue LEDs increased leaf fresh and dry weights of green leaf lettuce by $28 \%$ and $34 \%$, respectively. Addition of ultraviolet light did not induce any differences in growth and energy use efficiency in both lettuce cultivars, while supplementing green light with red plus blue LEDs reduced the vitamin C content of green leaf lettuce by $44 \%$ and anthocyanin content of purple leaf lettuce by 30\% compared with red plus blue LEDs, respectively. Spectral absorbencies of purple leaf lettuce grown under red plus blue LEDs supplemented with green light were lower in green light region compared with those grown under red plus blue LEDs, which was associated with anthocyanin contents. White plus red LEDs significantly increased leaf fresh and dry weights of purple leaf lettuce by 25\%, and no significant differences were observed in vitamin C and nitrate contents compared with white LEDs. Fresh weight, light and electrical energy use efficiencies of hydroponic green and purple leaf lettuces grown under white plus red LEDs were higher or no significant differences compared with those grown under red plus blue LEDs. In conclusion, white plus red LEDs were suggested to substitute for red plus blue LEDs in hydroponic lettuce (cv. Lvdie and Ziya) production in plant factories with artificial lighting.
\end{abstract}

Keywords: plant factory, hydroponic lettuce, light-emitting diodes (LED), light energy use efficiency, artificial lighting, absorption spectrum, anthocyanin content, photosynthetic pigments

DOI: $10.25165 /$ j.ijabe.20201302.5135

Citation: Yan Z N, He D X, Niu G H, Zhou Q, Qu Y H. Growth, nutritional quality, and energy use efficiency in two lettuce cultivars as influenced by white plus red versus red plus blue LEDs. Int J Agric \& Biol Eng, 2020; 13(2): 33-40.

\section{Introduction}

Chlorophylls and carotenoids are two classes of photosynthetic pigments in higher plants, which are used for light absorption that drive photosynthesis ${ }^{[1]}$. Chlorophyll a and chlorophyll b are dominant pigments in leaf cells, which absorb strongly in red (main absorption peak at 625-675 $\mathrm{nm}$ ) and blue (main absorption peak at 425-475 nm) regions of the spectrum ${ }^{[2]}$. Previous studies indicated that plant leaves absorbed over 90\% red and blue lights and approximately $70 \%$ green light ${ }^{[1,3]}$, demonstrating that red and blue lights are mostly absorbed by leaves. The chlorophyll pigments in vegetable leaves are sensitive to light quality, and may

\section{Received date: 2019-03-20 Accepted date: 2019-05-30}

Biographies: Zhengnan Yan, $\mathrm{PhD}$ Candidate, research interests: plant environmental physiology. Email: 1289619799@qq.com; Genhua Niu, Professor, research interests: plant environmental physiology. Email: gniu@ag.tamu.edu; Qing Zhou, Associate Professor, research interests: plant environmental physiology. Email: cauzhou@cau.edu.cn; Yinghua Qu, Professor, research interests: plant environmental physiology. Email: quyinghua@ cau.edu.cn;

*Corresponding author: Dongxian He, PhD, Professor, research interests: plant environmental physiology and plant factory technology. Key Lab. of Agricultural Engineering in Structure and Environment, Ministry of Agriculture and Rural Affairs, China Agricultural University, Beijing 100083, China. Tel/Fax: +86-10-62737550, Email: hedx@cau.edu.cn have variety-specific differences ${ }^{[4]}$. Chlorophyll contents were higher in lettuce (Lactuca sativa L.) grown under monochrome blue light than those grown under monochrome red light ${ }^{[5,6]}$, while opposite results were observed in tomato plants ${ }^{[7]}$. In addition, chlorophyll content ${ }^{[5]}$, fresh weight ${ }^{[8]}$, and nutritional quality ${ }^{[8,9]}$ of plants exposed to combination of red and blue lights were higher compared with monochrome red light. Therefore, suitable light quality provide by mixed red and blue lights were widely examined by previous studies in lettuce ${ }^{[5,10,11]}$, sweet basil ${ }^{[12]}$, pak choi ${ }^{[13]}$, and spinach $^{[14]}$.

In commercial horticulture industry, light-emitting diodes (LEDs) have tremendous potentiality owing to flexibility of spectral configuration, long life spans, and high energy conversion efficiency ${ }^{[15]}$. Lettuce is a major crop cultivated worldwide and it has been a model crop in studying its responses to LED quality ${ }^{[16-18]}$. Red and blue LEDs seem to be more suitable for lettuce production as a result of the maximum absorption spectrum of chlorophylls ${ }^{[5,19]}$. However, plants grown under natural environment are used to utilizing broad-wide spectrum by long-term evolution ${ }^{[20,21]}$. Except for red and blue lights, other parts of spectrum also affect plant growth and metabolites accumulation. Green light can penetrate upper leaves and could be absorbed by chloroplasts in the abaxial side ${ }^{[22]}$. Kim et al. ${ }^{[23]}$ observed that green leaf lettuce grown under red and blue LEDs 
supplemented with $24 \%$ green light had higher leaf fresh weight than those grown without green light. Net photosynthetic rate of lettuce leaf increased when red light supplemented with $10 \%$ green light but decreased when same fraction of green light was added in red and blue LEDs ${ }^{[24]}$. Addition of $8 \%$ green light with $68 \%$ red light led to bigger leaf area and higher leaf fresh weight in red leaf lettuce (cv. Sunmang), but not in green leaf lettuce (cv. Grand Rapid TBR) compared with lettuce grown with $66 \%$ red light ${ }^{[25]}$. Far-red light promotes plant growth by increasing leaf expansion instead of photosynthetic reaction ${ }^{[26,27]}$. Leaf and root fresh weights of red oakleaf lettuce (cv. Cherokee) seedlings increased significantly when far-red light was added to red and blue LEDs, but not in green butterhead lettuce (cv. Rex ${ }^{[28]}$. Similar trends were found in dry weight of red leaf lettuce (cv. Outredgeous) when far-red light was supplemented with red LEDs ${ }^{[29]}$. Ultraviolet (UV) light is applied for stimulating phytochemicals biosynthesis in plants grown under controlled environment due to its short wavelength and high energy ${ }^{[30,31]}$. Total anthocyanin, flavonoid and phenolic contents of red leaf lettuce exposed to UV light increased remarkably than those without UV light ${ }^{[32]}$. Similar results were also reported by Lee et al. ${ }^{[30]}$. These studies suggested that growth and nutritional quality of plants could be regulated by supplemental other lights and different cultivars have various morphological and physiological responses to light quality.

Considering carbohydrate accumulation and energy use efficiency, white LEDs were suggested to substitute for fluorescent lamps in lettuce production in plant factory with artificial lighting $^{[33]}$. White plus red LEDs were found more suitable for growth of hydroponic lettuce compared with fluorescent lamps at seedling stage $\mathrm{e}^{[27]}$ and its subsequent cultivation stage $\mathrm{e}^{[17]}$. Chen et al. ${ }^{[20]}$ also indicated that white plus red LEDs resulted in vigorous and compact lettuce than those grown under white LEDs alone and inferred that lettuce yield would increase with more red light added in white LEDs. However, excess red light may have negative influences on lettuce growth and phytochemical accumulation. Yan et al. ${ }^{[34]}$ examined proper red light amounts (24.4\% red light) added in white LEDs for purple leaf lettuce production in consideration of growth, nutritional values, and energy use efficiencies. However, few studies compared white plus red LEDs and red plus blue LEDs in photosynthetic pigments, absorption spectrum and energy use efficiency in different lettuce cultivars.

In order to find out suitable LED quality provided by white plus red LEDs or red plus blue LEDs, chlorophyll contents, growth, spectral characteristics of lettuce leaf, nutritional quality, and energy use efficiency of green and purple leaf lettuces were investigated in a plant factory with artificial lighting. The results can be a practical way for tailoring LEDs in lettuce production in different cultivars.

\section{Materials and methods}

\subsection{Plant materials and growth conditions}

Seeds of green and purple leaf lettuces (Lactuca sativa $\mathrm{L} . \mathrm{cv}$. Lvdie and Ziya) were sown in sponge cube $(23 \mathrm{~mm} \times 23 \mathrm{~mm} \times$ $23 \mathrm{~mm}$ ) filled with deionized water, and then were put in plastic containers $(520 \mathrm{~mm} \times 360 \mathrm{~mm} \times 90 \mathrm{~mm})$ in a walk-in growth chamber (China Agricultural University, Beijing, China). Seven day-old lettuce seedlings were divided into 128-cell trays and then cultivated continuously for 13 days. Uniform lettuce seedlings were selected randomly and then transplanted to hydroponic beds
$(1200 \mathrm{~mm} \times 900 \mathrm{~mm} \times 70 \mathrm{~mm})$ with $4 \mathrm{~mm}$ thickness, which were made of acrylonitrile butadiene styrene. Each bed held 35 plants at 20 days after sowing. According to previous study ${ }^{[27]}$, light intensity at $200 \mu \mathrm{mol} /\left(\mathrm{m}^{2} \cdot \mathrm{s}\right)$ with a $16 \mathrm{~h} / \mathrm{d}$ photoperiod provided by white plus red LEDs with a red light to blue light ratio (R:B ratio) of 2.2 were applied during seedling stage. Air temperature and relative humidity were maintained at $(22 \pm 1)^{\circ} \mathrm{C} /(18 \pm 1)^{\circ} \mathrm{C}$ and $(65 \% \pm 5 \%) /(75 \% \pm 10 \%)$ at photoperiod/dark period, respectively. $\mathrm{CO}_{2}$ concentration was maintained at $(800 \pm 50) \mu \mathrm{mol} / \mathrm{mol}$ at photoperiod and without control at dark period. The hydroponic lettuces were harvest at 20 days after transplanting.

Yamasaki lettuce nutrient solution was used and provided by the following components, mg/L: $\mathrm{Ca}\left(\mathrm{NO}_{3}\right)_{2} \cdot 4 \mathrm{H}_{2} \mathrm{O}, 236 ; \mathrm{KNO}_{3}$, 404; $\mathrm{MgSO}_{4} \cdot 7 \mathrm{H}_{2} \mathrm{O}, 123 ; \mathrm{NH}_{4} \mathrm{H}_{2} \mathrm{PO}_{4}$, 57; Fe-DTPA (7\%), 28.571; $\mathrm{MnSO}_{4} \cdot \mathrm{H}_{2} \mathrm{O}, 0.615 ; \mathrm{CuSO}_{4} \cdot 5 \mathrm{H}_{2} \mathrm{O}, 0.039 ; \mathrm{ZnSO}_{4} \cdot 7 \mathrm{H}_{2} \mathrm{O}, 0.088$; $\mathrm{H}_{3} \mathrm{BO}_{3}$, 1.127; (NH4) ${ }_{6} \mathrm{Mo}_{6} \mathrm{O}_{24} 4 \mathrm{H}_{2} \mathrm{O}, 0.013$, respectively. The electrical conductivity and $\mathrm{pH}$ of Yamasaki lettuce nutrition solution were adjusted at $1.0-1.2 \mathrm{mS} / \mathrm{cm}$ and 6.0-6.5, respectively. Tap water were applied to irrigate lettuce seedlings once a day after 2 days after sowing. 1/4 strength and 1/2 strength of Yamasaki lettuce nutrient solution were used at cotyledon stage and 1-2 true leaves stage, respectively. A full strength of Yamasaki lettuce nutrient solution was applied upon unfolding of the $2^{\text {nd }}$ true leaf and the nutrient solution was replaced every 7 days during growth period.

\subsection{LED lighting treatments}

Lettuce were grown under six kinds of LED quality provided by white LEDs with a R:B ratio of 0.9 (W), white plus red LEDs with a $\mathrm{R}: \mathrm{B}$ ratio of 2.2 (WR), red plus blue LEDs with a $\mathrm{R}: \mathrm{B}$ ratio of 4.6 (RB). Ultraviolet (RBUV), green (RBG) or far-red LEDs (RBFr) were added to red plus blue LEDs with R:B ratios of 5.1, 5.4, and 5.6, respectively. LEDs mentioned above were manufactured by Beijing Lighting Valley Technology Co., Ltd. and with alternating current supply. A mirror-like stainless steel plate $(1200 \mathrm{~mm} \times 900 \mathrm{~mm} \times 0.4 \mathrm{~mm})$ was installed above LEDs. The wall was made of aluminum plastic plate with small holes for ventilation. Spectral distributions of above light environment were measured by a fiber spectrometer (AvaField-2, Avantes Inc., The Netherland) at $15 \mathrm{~cm}$ below the LED lamps with wavebands ranging from $300 \mathrm{~nm}$ to $800 \mathrm{~nm}$ (Figure 1). The photon flux of ultraviolet (UV, 300-399 nm), blue (B, 400-499 nm), green (G, 500-599 nm), red (R, 600-699 nm) and far-red (Fr, 700-800 nm) lights were integrated based on the spectral distributions (Table 1).

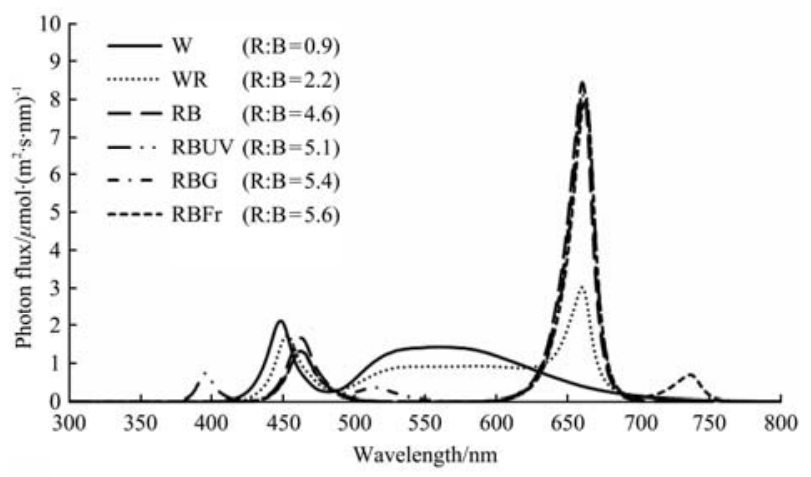

Figure 1 Spectral distribution of LED lighting environment at light intensity of $250 \mu \mathrm{mol} /\left(\mathrm{m}^{2} \cdot \mathrm{s}\right)$ provided by white LEDs (W), white plus red LEDs (WR), red plus blue LEDs (RB), and red plus blue LEDs supplemented with ultraviolet (RBUV), green (RBG), or far-red light (RBFr), respectively 
Table 1 Spectral distributions of white LEDs (W), white plus red LEDs (WR), red plus blue LEDs (RB), and red plus blue LEDs supplemented with ultraviolet (RBUV), green (RBG), or far-red light (RBFr), respectively

\begin{tabular}{|c|c|c|c|c|c|c|c|}
\hline & & & Sp & ctral dis & tribution & & \\
\hline & & W & WR & $\mathrm{RB}$ & RBUV & RBG & RBFr \\
\hline Photon flux & $(300-800 \mathrm{~nm})$ & 100.0 & 100.0 & 100.0 & 100.0 & 100.0 & 100.0 \\
\hline Ultraviolet lig & $(300-399 \mathrm{~nm})$ & 0.0 & 0.0 & 0.0 & 3.4 & 0.0 & 0.0 \\
\hline Blue light & $(400-499 \mathrm{~nm})$ & 27.0 & 20.4 & 17.7 & 15.7 & 14.8 & 13.9 \\
\hline Green light & $(500-599 \mathrm{~nm})$ & 46.9 & 33.9 & 0.6 & 0.5 & 5.0 & 0.4 \\
\hline Red light & $(600-699 \mathrm{~nm})$ & 24.2 & 44.1 & 81.5 & 80.2 & 80.0 & 78.1 \\
\hline Far-red light & $(700-800 \mathrm{~nm})$ & 1.9 & 1.6 & 0.2 & 0.2 & 0.2 & 7.6 \\
\hline & & 0.9 & 2.2 & 4.6 & 5.1 & 5.4 & 5.6 \\
\hline & & 12.7 & 27.6 & - & - & - & 10.3 \\
\hline
\end{tabular}

Note: Data are photon flux-based compositions of ultraviolet, blue, green, red and far-red lights. R:B, red light to blue light ratio. R:Fr, red light to far-red light ratio.

\subsection{Measurements}

2.3.1 Chlorophyll contents and photosynthetic characteristic of hydroponic lettuce leaves

Six uniform plants were randomly chosen in each treatment. The $3^{\text {rd }}$ fully expanded leaf from the top was used for chlorophyll contents and photosynthetic characteristic measurements. Approximate $0.1 \mathrm{~g}$ of lettuce leaves were cut into small pieces and extracted in $80 \%$ acetone for $48 \mathrm{~h}$. The absorbance of the extract at wavelength $663 \mathrm{~nm}$ and $645 \mathrm{~nm}$ were measured with a UV-VIS spectrophotometer (UV3150, Shimatsu Corporation, Japan). Chlorophyll a and chlorophyll b contents were calculated according to Arnon ${ }^{[35]}$ and were used to calculate total chlorophyll content. A portable photosynthesis system (LI-6400XT, LI-COR Inc., USA) were applied to measure net photosynthetic rate. The light intensity, leaf temperature and $\mathrm{CO}_{2}$ concentration in the leaf chamber (equipped with in-built red and blue LEDs) were controlled at $250 \mu \mathrm{mol} /\left(\mathrm{m}^{2} \cdot \mathrm{s}\right), 22^{\circ} \mathrm{C}$, and $800 \mu \mathrm{mol} / \mathrm{mol}$, respectively.

\subsubsection{Spectral characteristics of hydroponic lettuce leaves}

Five uniform lettuce plants were randomly selected in each treatment, and one side of the main vein of the third fully expanded leaf from the top was measured for the spectral characteristics. The spectral transmittance and reflectance of lettuce leaves were examined by above UV-VIS spectrophotometer with scanning wavelength range from $300 \mathrm{~nm}$ to $800 \mathrm{~nm}$. The spectral absorbances of lettuce leaves were calculated by the transmittance and reflectance.

\subsubsection{Growth characteristics of hydroponic lettuces}

Six uniform lettuce plants were randomly selected at harvest (20 days after transplanting) in each treatment. Fresh leaf and roots were oven-dried at $105^{\circ} \mathrm{C}$ for $3 \mathrm{~h}$ and subsequently set to $80^{\circ} \mathrm{C}$ until constant weight. Fresh and dry weights of the lettuce leaf and roots were measured by an electronic analytical balance (FA1204B, Bioon Group, China).

\subsubsection{Nutritional quality of hydroponic lettuces}

Samples were randomly chosen from fresh leaves of six uniform lettuce plants in each treatment. Leaf samples were cut into small pieces and mixed for measuring vitamin C, nitrate, and anthocyanin contents. 2,6-dichlorophenol indophenol titration $\operatorname{method}^{[36]}$, coloration method of sulfosalicyclic $\operatorname{acid}^{[37]}$, and spectrometric method ${ }^{[38]}$ were applied to examine vitamin C, nitrate and anthocyanin contents of hydroponic lettuce leaves, respectively.
Nitrate content was determined by above UV-VIS spectrophotometer at wavelength of $410 \mathrm{~nm}$ for absorbance, anthocyanin content was calculated by the absorbance of extraction solution at wavelength of $530 \mathrm{~nm}$ and $600 \mathrm{~nm}$.

\subsubsection{Light and electrical energy use efficiencies}

Light energy use efficiency (LUE) and electrical energy use efficiency (EUE) were calculated according to Kozai and $\mathrm{Niu}^{[39]}$, which were defined as: LUE $=f \times D /$ PAR and EUE $=h \times$ LUE. Where, $f$ is conversion factor from dry mass to chemical energy (about $20 \mathrm{MJ} / \mathrm{kg}$ ), $D$ is the dry mass increase rate of lettuce plants, $\mathrm{kg} /\left(\mathrm{m}^{2} \cdot \mathrm{h}\right), \quad$ PAR is the photosynthetically active radiation, $\mathrm{MJ} /\left(\mathrm{m}^{2} \cdot \mathrm{h}\right), h$ is the conversion coefficient from electrical energy to PAR energy. From practical measurement, $h$ in white LEDs, white plus red LEDs, red plus blue LEDs, and red plus blue LEDs supplemented with ultraviolet, green, or far-red light were 0.455 , $0.368,0.343,0.332,0.333$ and 0.337 , respectively. Power consumption of LED lights in each treatment were measured by smart metering (TP9004, Shenzhen Northmeter Co., Ltd., China) and used for calculating power consumption based on $100 \mathrm{~g}$ fresh weight of leaves or $1 \mathrm{~g}$ dry weight of all plant by Zhang et al. ${ }^{[17]}$.

\subsection{Statistical analysis}

Statistical analysis was performed with SPSS 18.0 software (IBM, Inc., Chicago, IL, USA) followed by the least significant difference (LSD) test to compare the means between treatments $(p<0.05)$. The results were reported as the mean \pm standard deviation (SD) values.

\section{Results and discussion}

\subsection{Chlorophyll contents, photosynthesis, and spectral} characteristics of hydroponic lettuce leaves

Lettuce grown under red plus blue LEDs supplemented with UV, green or far-red light did not exhibit significant differences in chlorophyll contents compared with red plus blue LEDs, irrespective of lettuce cultivars (Table 2). Similar trends were found in net photosynthetic rate of green leaf lettuce. However, net photosynthetic rate of purple leaf lettuce grown under red plus blue LEDs supplemented with $4.4 \%$ green light was lower compared with those grown under red plus blue LEDs, which was attributed to the fact that green light was not effectively absorbed by upper leaves (Figure 2). Kang et al. ${ }^{[24]}$ observed that net photosynthetic rate of green leaf lettuce was significantly decreased when $10 \%$ green light were added in red plus blue LEDs. However, when $5 \%$ and $24 \%$ green lights were added in red plus blue LEDs and white plus red LEDs, respectively, no remarkable differences were found in chlorophyll contents and net photosynthetic rate of green leaf lettuce ${ }^{[23,40]}$. Meanwhile, net photosynthetic rate of purple leaf lettuce grown under red plus blue LEDs supplemented with green light was lower compared with those grown under red plus blue LEDs, although no significant differences were observed in chlorophyll contents of purple leaf lettuce between two treatments. This may due to the differences of carotenoids contents, which acted as auxiliary photoreceptors of chlorophyll with main absorption spectrum in blue region ${ }^{[2]}$. No remarkable differences were observed in chlorophyll contents and net photosynthetic rate of two lettuce cultivars grown under red plus blue LEDs and white plus red LEDs, which was consistent with the study reported by Mickens et al. ${ }^{[41]}$

The light absorption of lettuce leaf was mainly in red (600$699 \mathrm{~nm})$ and blue light (400-499 nm) regions with absorbance 
peaks at about $680 \mathrm{~nm}$ and then drastically decreased at wavelengths more than $680 \mathrm{~nm}$ for both cultivars (Figure 2). The absorption spectrum of lettuce leaves grown under different LEDs were similar in blue and red regions, but significant differences were observed in green (500-599 nm) region in purple leaf lettuce. The spectrum absorbances of lettuce leaves were lower in green light regions owing to higher transmittance and reflectance in this region. Purple leaf lettuce grown under red plus blue LEDs and red plus blue supplemented with green light had highest and lowest absorbances in green light region among all treatment, respectively. These differences were attributed to the facts that lettuce grown under red plus blue LEDs contained higher anthocyanin contents than those grown under red plus blue LEDs supplemented with green light (Figure 3). Similar trends were reported by previous studies $^{[42,43]}$, demonstrating that the differences of absorption spectrum in green light region was due to anthocyanin contents. Addition of $4.4 \%$ green light in red plus blue LEDs increased the reflectance of purple lettuce leaves, and the reflectance in green light region was significantly higher than that in red and blue light region, suggesting that more fraction of visible light passed through upper leaves. The results were consistent with the previous study reported by Son and $\mathrm{Oh}^{[25]}$, who observed that lettuce grown under LEDs containing green light exhibited a higher transmittance in green wavelength than red and blue wavelength.

Table 2 Chlorophyll contents and photosynthetic characteristics of hydroponic green and purple leaf lettuces (cv. Lvdie and Ziya) grown under white LEDs (W), white plus red LEDs (WR), red plus blue LEDs (RB), and red plus blue LEDs supplemented with ultraviolet (RBUV), green (RBG), or far-red light (RBFr), respectively

\begin{tabular}{|c|c|c|c|c|c|c|c|}
\hline $\begin{array}{l}\text { Lettuce } \\
\text { cultivar }\end{array}$ & $\begin{array}{l}\text { Lighting } \\
\text { treatment }\end{array}$ & $\begin{array}{l}\text { Chlorophyll a content } \\
\qquad / \mathrm{mg} \cdot \mathrm{g}^{-1}\end{array}$ & $\begin{array}{r}\text { Chlorophyll b } \\
/ / \mathrm{mg} \cdot \mathrm{g}^{-1}\end{array}$ & content & $\begin{array}{r}\text { Total chlorophyl } \\
/ \mathrm{mg} \cdot \mathrm{g}^{-1}\end{array}$ & Il content & $\begin{array}{l}\text { Net photosynthetic rate } \\
\qquad / \mu \mathrm{mol} \cdot \mathrm{m}^{-2} \cdot \mathrm{s}^{-1}\end{array}$ \\
\hline \multirow{5}{*}{$\begin{array}{l}\text { cv. Lvdie } \\
\text { (Green leaf) }\end{array}$} & W & $1.01 \pm 0.34 \quad$ NS & $0.31 \pm 0.10$ & NS & $1.32 \pm 0.44$ & NS & $11.3 \pm 0.7$ NS \\
\hline & $\mathrm{RB}$ & $0.98 \pm 0.24 \mathrm{NS}$ & $0.32 \pm 0.08$ & NS & $1.30 \pm 0.31$ & NS & $12.0 \pm 1.4$ NS \\
\hline & RBUV & $1.12 \pm 0.32 \mathrm{NS}$ & $0.36 \pm 0.10$ & NS & $1.48 \pm 0.42$ & NS & $11.7 \pm 1.6 \quad \mathrm{NS}$ \\
\hline & RBG & $0.96 \pm 0.27 \quad$ NS & $0.30 \pm 0.08$ & NS & $1.26 \pm 0.35$ & NS & $11.2 \pm 0.7$ NS \\
\hline & $\mathrm{RBFr}$ & $0.94 \pm 0.21 \quad$ NS & $0.31 \pm 0.07$ & NS & $1.26 \pm 0.27$ & NS & $11.5 \pm 1.0$ \\
\hline \multirow{5}{*}{$\begin{array}{c}\text { cv. Ziya } \\
\text { (Purple leaf) }\end{array}$} & W & $0.51 \pm 0.07 \quad$ a & $0.16 \pm 0.02$ & a & $0.66 \pm 0.09$ & a & $6.3 \pm 0.6 \quad \mathrm{~b}$ \\
\hline & WR & $0.39 \pm 0.13 \quad \mathrm{ab}$ & $0.12 \pm 0.04$ & $\mathrm{~b}$ & $0.51 \pm 0.17$ & $\mathrm{ab}$ & $7.0 \pm 0.6 \quad \mathrm{ab}$ \\
\hline & $\mathrm{RB}$ & $0.37 \pm 0.11 \quad a b$ & $0.11 \pm 0.03$ & bc & $0.48 \pm 0.13$ & $\mathrm{~b}$ & $7.9 \pm 0.4 \quad \mathrm{a}$ \\
\hline & RBUV & $0.35 \pm 0.11 \quad b$ & $0.11 \pm 0.03$ & bc & $0.46 \pm 0.14$ & $\mathrm{~b}$ & $6.8 \pm 1.4$ \\
\hline & RBG & $0.38 \pm 0.05 \quad a b$ & $0.11 \pm 0.01$ & bc & $0.48 \pm 0.06$ & $\mathrm{~b}$ & $6.2 \pm 1.1 \quad \mathrm{~b}$ \\
\hline
\end{tabular}

Note: Different letters in the same column indicate significant differences at the $5 \%$ level, according to LSD's multiple comparison ( $n=6)$.
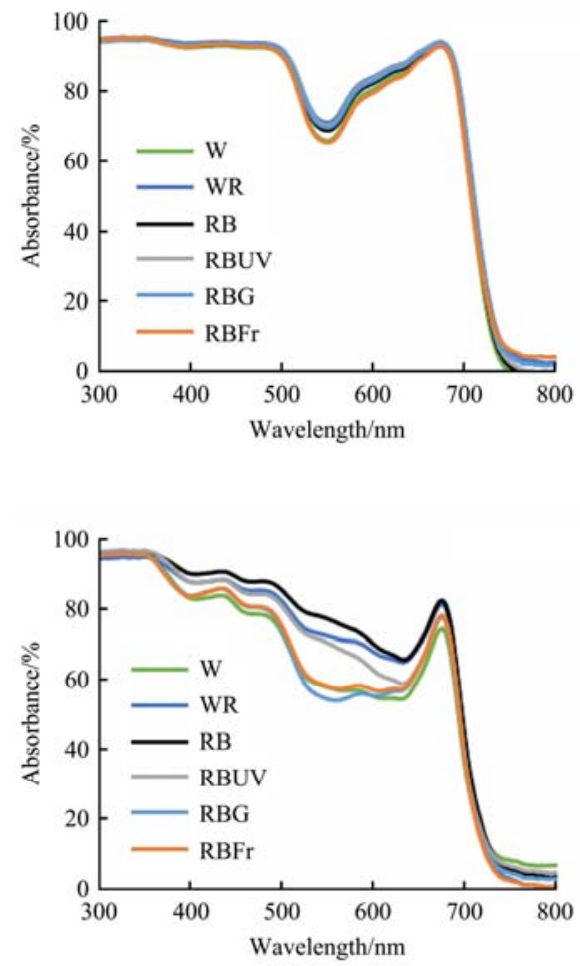

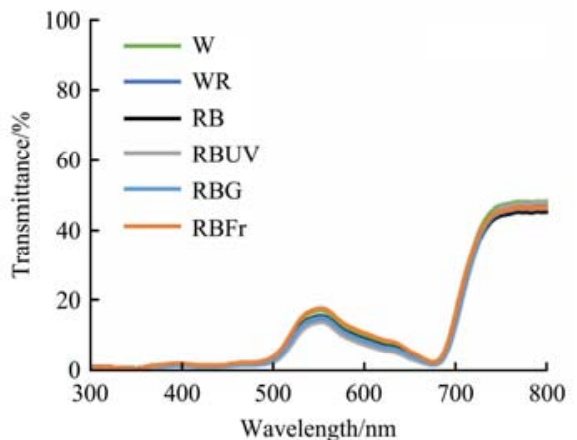

a. cv. Lvdie
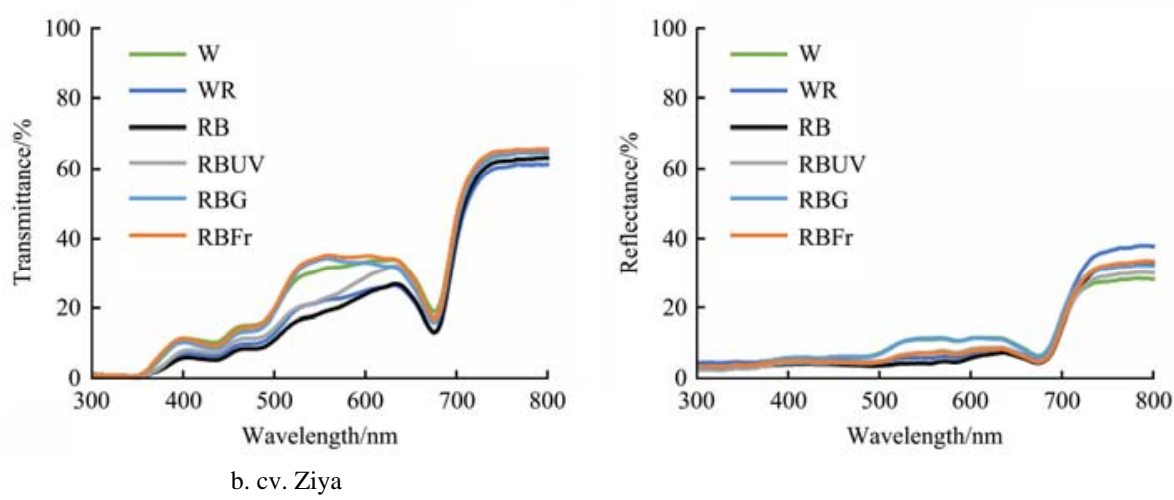

Figure 2 Spectral characteristics of hydroponic green and purple leaf lettuces (cv. Lvdie and Ziya) grown under white LEDs (W), white plus red LEDs (WR), red plus blue LEDs (RB), and red plus blue LEDs supplemented with ultraviolet (RBUV), green (RBG), or far-red light (RBFr), respectively 

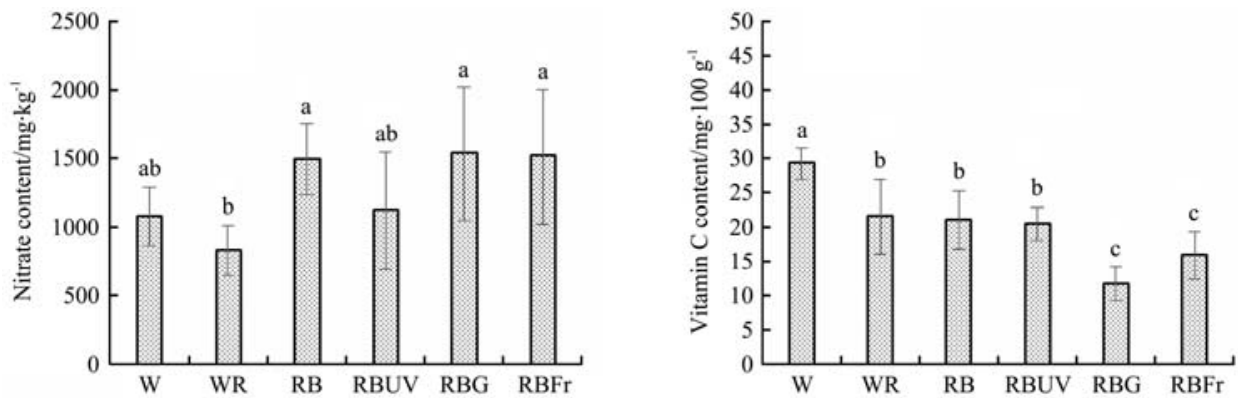

a. cv. Lvdie
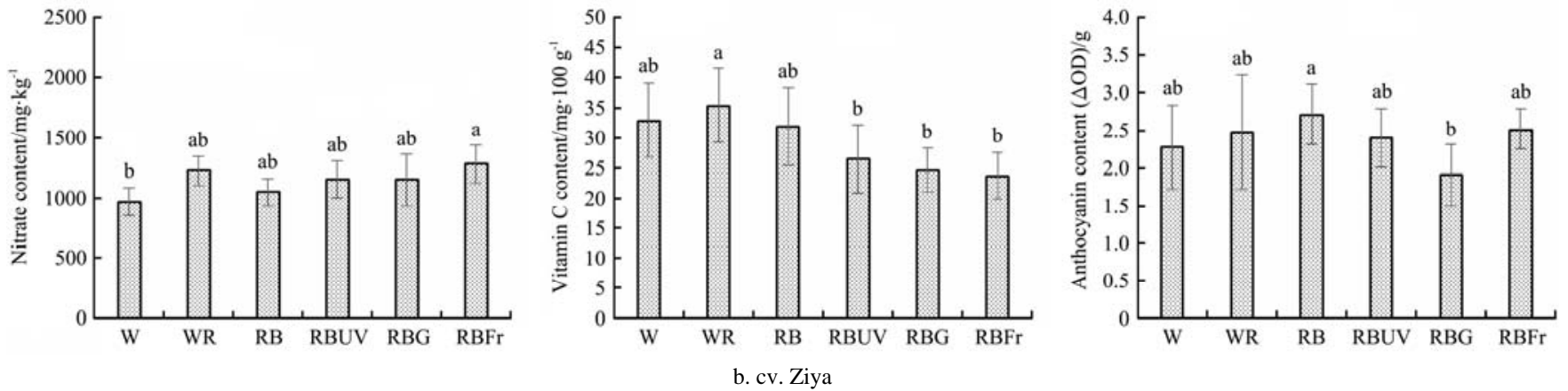

Figure 3 Nitrate, vitamin C and anthocyanin contents of hydroponic green and purple leaf lettuces (cv. Lvdie and Ziya) grown under white LEDs (W), white plus red LEDs (WR), red plus blue LEDs (RB), and red plus blue LEDs supplemented with ultraviolet (RBUV), green

(RBG), or far-red light (RBFr), respectively

\subsection{Growth of hydroponic lettuces}

No significant differences were observed in leaf fresh weight of purple leaf lettuce grown under red plus blue LEDs supplemented with UV, green or far-red light compared with those grown under red plus blue LEDs. However, leaf fresh weight of green leaf lettuce increased significantly by $22.9 \%$ and $27.5 \%$ when $4.4 \%$ green light and $7.4 \%$ far-red light were added in red plus blue LEDs, respectively (Table 3). The results demonstrated that different colored lettuces may have various responses to LED quality. Meng and Runkle ${ }^{[28]}$ observed that supplemental far-red light in red plus blue LEDs resulted in higher leaf and root fresh weights of red oakleaf lettuce seedlings (cv. Cherokee), however, no significant differences were found in green butterhead lettuce seedlings (cv. Rex). Addition of far-red light in white fluorescent lamps also increased leaf fresh weight of red leaf lettuce (cv. Red Cross) by $28.2 \%^{[16]}$. This may due to the facts that addition of far-red light leads to the lighting environment with a lower R:Fr ratio, which acts as a signal for plants and leads to shade-avoidance responses, such as increases shoot elongation and induces larger leaves. As a result, far-red light promoted the biomass accumulation by increasing lettuce leaves area and thereby increasing the area of light interception ${ }^{[26,27]}$. Lee et al. ${ }^{[44]}$ observed that leaf and root fresh weights of red leaf lettuce grown under LEDs with lower R:Fr ratio at 1.2 were 1.3 and 1.6 times higher than those grown under higher R:Fr ratio at 4.1. Addition of $4.4 \%$ green light or $3.4 \%$ UV light had no significant effects in leaf and root dry weights in both lettuce cultivars (Table 3). Similarly, Kim et al. ${ }^{[0]}$ observed that no significant differences were found in leaf area, total chlorophyll contents, and leaf dry weight of lettuce when $5 \%$ green light were added in red plus blue LEDs. Additional of 9\% green light in white LEDs also did not lead to any differences in chlorophyll contents, fresh and dry weights of lettuce at 28 days after sowing ${ }^{[41]}$. The results were likely due to the facts that too small fraction or amount of supplemental light in LEDs would not induce any differences in carbohydrate accumulation.
A higher red light fraction combined with blue or white light led to higher yield of lettuce ${ }^{[5,34]}$, pepper seedlings ${ }^{[45]}$, and sweet basil $^{[12]}$. White plus red LEDs resulted in higher leaf and root weights of purple leaf lettuce compared with white LEDs, but no significant differences were observed in green leaf lettuce. Previous studies indicated that $14.0 \%{ }^{[41]}, 18.0 \%^{[20]}$ and $24.4 \%^{[34]}$ red lights added in white LEDs resulted in higher yield of lettuces. However, when white fluorescent lamps were applied as base lighting source, supplemental $33.4 \%$ red light had no remarkable influences in fresh and dry weights of red leaf lettuce ${ }^{[16]}$. Green leaf lettuce grown under white and white plus red LEDs were $22.6 \%$ and $25.9 \%$ higher in leaf fresh weight than those grown under red plus blue LEDs. However, no significant differences were observed in leaf and root fresh weights of purple lettuce grown under red plus blue LEDs and white plus red LEDs (Table 3). Mickens et al. ${ }^{[41]}$ found that fresh weight of lettuce was higher exposed to white LEDs with $32.0 \%$ red light or white plus red LEDs with $46.0 \%$ red light than those exposed to red plus blue LEDs with $60.0 \%$ red light. Similarly, Han et al. ${ }^{[46]}$ observed that leaf area and total fresh weight of lettuce grown under broad white or narrow white LEDs were higher than those grown under red plus blue LEDs. Leaf fresh weight of green and red leaf lettuces grown under warm white LEDs with $54.6 \%$ red light also led to higher yield than those grown under red plus blue LEDs with $66.7 \%$ red light ${ }^{[47]}$. These studies indicated that white or white plus red LEDs resulted in similar or higher carbohydrate accumulation of lettuce than red plus blue LEDs, which could be used for lettuce production in different cultivars.

\subsection{Nutritional values of hydroponic lettuce}

Supplementation of UV, green or far-red light in red plus blue LEDs did not affect nitrate contents in green and purple leaf lettuces (Figure 3). No significant differences were observed in anthocyanin content in purple lettuce when UV light with light intensity of $8.5 \mu \mathrm{mol} /\left(\mathrm{m}^{2} \cdot \mathrm{s}\right)$ or far-red light with light intensity of $18.5 \mu \mathrm{mol} /\left(\mathrm{m}^{2} \cdot \mathrm{s}\right)$ were added in red and blue LEDs, respectively (Figure 3). Similarly, Samuoliene et al. ${ }^{[48]}$ found that addition of 
UV light with light intensity of $4 \mu \mathrm{mol} /\left(\mathrm{m}^{2} \cdot \mathrm{s}\right)$ did not induce any discrepancies in anthocyanin content. However, the results were slightly different from previous study reported by Li and Kubota ${ }^{[16]}$, who found that anthocyanin contents were significantly increased by $11.2 \%$ and decreased by $40.5 \%$ when UV light with light intensity of $16.3 \mu \mathrm{mol} /\left(\mathrm{m}^{2} \cdot \mathrm{s}\right)$ and far-red light with light intensity of $154 \mu \mathrm{mol} /\left(\mathrm{m}^{2} \cdot \mathrm{s}\right)$ were added in white LEDs, respectively. The differences were probably attributed to the amount of the light supplemented and the remaining spectral composition or cultivars. Supplementary green light in red plus blue LEDs reduced vitamin C content by $44.3 \%$ in green leaf lettuce and anthocyanin content by $29.5 \%$ in purple leaf lettuce. Previous studies indicated that addition of $1.7 \%{ }^{[29]}$ or $17.8 \%^{[16]}$ green light had no additional effects on anthocyanin contents. No significant differences were found in vitamin $\mathrm{C}$ and anthocyanin contents in both lettuce cultivars grown under white plus red LEDs and red plus blue LEDs. There were no remarkable discrepancies in nitrate, vitamin $\mathrm{C}$ and anthocyanin contents in purple leaf lettuce grown under white LEDs and white plus red LEDs. The results were consistent with previous studies, who found that supplemental $33.4 \%$ red light in white fluorescent lamps ${ }^{[16]}$ and supplemental $14.1 \%$ red light in white plus red $\operatorname{LEDs}^{[17]}$ did not have remarkable effects in anthocyanin content and nitrate contents of lettuce, respectively.

3.4 Energy use efficiencies of LED lighting for hydroponic lettuces production

Optimal spectrum of LEDs should be carefully selected to maximize the carbohydrate accumulation and in consideration of energy use efficiencies of plants. Supplementation of UV, green or far-red light in red plus blue LEDs had no significantly effects in power consumption based on fresh and dry weights of purple leaf lettuce, LUE and EUE (Table 4). However, addition of far-red light in red plus blue LEDs resulted in lower consumption based on fresh and dry weights of green leaf lettuce, and higher LUE and EUE. The results were attributed to the facts that addition of far-red light in red plus blue LEDs led to higher lettuce yield. No significant differences were observed in energy use efficiencies of purple leaf lettuce between red plus blue LEDs and white plus red LEDs. However, white plus red LEDs led to higher LUE and EUE of green leaf lettuce than those exposed to red plus blue LEDs. LUE and EUE of purple leaf lettuce grown under white plus red LEDs were $45.5 \%$ and $18.2 \%$ higher than those grown under white LEDs, respectively, which were consist with previous study reported by Yan et al. ${ }^{[34]}$, who found that LUE and EUE increased by more than $22.7 \%$ and $7.1 \%$ when $24.4 \%$ red light were added in white LEDs, respectively.

Table 3 Fresh and dry weights of hydroponic green and purple leaf lettuces (cv. Lvdie and Ziya) grown under white LEDs (W), white plus red LEDs (WR), red plus blue LEDs (RB), and red plus blue LEDs supplemented with ultraviolet (RBUV), green (RBG), or far-red light (RBFr), respectively

\begin{tabular}{|c|c|c|c|c|c|c|c|c|c|}
\hline \multirow{2}{*}{$\begin{array}{l}\text { Lettuce } \\
\text { cultivar }\end{array}$} & \multirow{2}{*}{$\begin{array}{c}\begin{array}{c}\text { Lighting } \\
\text { treatment }\end{array} \\
\mathrm{W}\end{array}$} & \multicolumn{2}{|c|}{$\begin{array}{l}\text { Leaf fresh weight } \\
\text { /g per plant }\end{array}$} & \multicolumn{2}{|c|}{$\begin{array}{l}\text { Root fresh weight } \\
\text { /g per plant }\end{array}$} & \multicolumn{2}{|c|}{$\begin{array}{l}\text { Leaf dry weight } \\
\text { /g per plant }\end{array}$} & \multicolumn{2}{|c|}{$\begin{array}{l}\text { Root dry weight } \\
\text { /g per plant }\end{array}$} \\
\hline & & $79.22 \pm 5.10$ & $\mathrm{a}$ & $12.89 \pm 0.67$ & $\mathrm{a}$ & $3.46 \pm 0.48$ & $\mathrm{ab}$ & $0.63 \pm 0.06$ & $\mathrm{ab}$ \\
\hline \multirow{5}{*}{$\begin{array}{l}\text { cv. Lvdie } \\
\text { (Green leaf) }\end{array}$} & WR & $81.33 \pm 10.73$ & a & $12.54 \pm 2.66$ & $\mathrm{ab}$ & $3.72 \pm 0.84$ & a & $0.66 \pm 0.12$ & a \\
\hline & $\mathrm{RB}$ & $64.61 \pm 7.10$ & b & $10.67 \pm 1.65$ & $\mathrm{~b}$ & $2.79 \pm 0.42$ & $\mathrm{~b}$ & $0.46 \pm 0.05$ & $\mathrm{~b}$ \\
\hline & RBUV & $71.23 \pm 11.45$ & $\mathrm{ab}$ & $10.83 \pm 2.15$ & $\mathrm{~b}$ & $2.96 \pm 0.51$ & $\mathrm{~b}$ & $0.56 \pm 0.07$ & $\mathrm{~b}$ \\
\hline & RBG & $79.43 \pm 6.22$ & $\mathrm{a}$ & $11.61 \pm 1.05$ & $\mathrm{ab}$ & $3.48 \pm 0.32$ & $\mathrm{ab}$ & $0.55 \pm 0.07$ & $\mathrm{~b}$ \\
\hline & $\mathrm{RBFr}$ & $82.39 \pm 11.80$ & a & $13.56 \pm 0.80$ & $\mathrm{a}$ & $3.73 \pm 0.73$ & a & $0.62 \pm 0.10$ & $\mathrm{ab}$ \\
\hline \multirow{6}{*}{$\begin{array}{c}\text { cv. Ziya } \\
\text { (Purple leaf) }\end{array}$} & W & $38.46 \pm 2.27$ & $\mathrm{~b}$ & $6.91 \pm 0.17$ & c & $1.91 \pm 0.11$ & c & $0.31 \pm 0.03$ & c \\
\hline & WR & $48.12 \pm 8.68$ & a & $8.15 \pm 0.99$ & $\mathrm{~b}$ & $2.46 \pm 0.42$ & $\mathrm{~b}$ & $0.40 \pm 0.03$ & $a b$ \\
\hline & $\mathrm{RB}$ & $51.53 \pm 4.28$ & $\mathrm{a}$ & $9.32 \pm 0.92$ & $\mathrm{ab}$ & $2.87 \pm 0.19$ & a & $0.40 \pm 0.04$ & $\mathrm{ab}$ \\
\hline & RBUV & $48.83 \pm 1.87$ & a & $9.27 \pm 1.23$ & $\mathrm{ab}$ & $2.90 \pm 0.48$ & $\mathrm{a}$ & $0.42 \pm 0.05$ & $\mathrm{ab}$ \\
\hline & RBG & $48.74 \pm 3.49$ & a & $8.05 \pm 1.30$ & bc & $2.60 \pm 0.25$ & $\mathrm{ab}$ & $0.36 \pm 0.04$ & $\mathrm{~b}$ \\
\hline & $\mathrm{RBFr}$ & $47.76 \pm 4.37$ & a & $10.06 \pm 1.54$ & $\mathrm{a}$ & $2.65 \pm 0.27$ & $\mathrm{ab}$ & $0.45 \pm 0.05$ & a \\
\hline
\end{tabular}

Note: Different letters in the same column indicate significant differences at the 5\% level, according to LSD’s multiple comparison ( $n=6)$.

Table 4 Energy use efficiencies of hydroponic green and purple leaf lettuces (cv. Lvdie and Ziya) grown under white LEDs (W), white plus red LEDs (WR), red plus blue LEDs (RB), and red plus blue LEDs supplemented with ultraviolet (RBUV), green (RBG), or far-red light (RBFr), respectively

\begin{tabular}{|c|c|c|c|c|c|}
\hline $\begin{array}{l}\text { Lettuce } \\
\text { cultivar }\end{array}$ & $\begin{array}{l}\text { Lighting } \\
\text { treatment }\end{array}$ & $\begin{array}{l}\text { Power consumption based on } \\
\text { fresh weight/kWh per 100g FW }\end{array}$ & $\begin{array}{l}\text { Power consumption based on } \\
\text { dry weight/kWh per 1g DW }\end{array}$ & $\begin{array}{l}\text { Light energy } \\
\text { use efficiency }\end{array}$ & $\begin{array}{l}\text { Electrical energy } \\
\text { use efficiency }\end{array}$ \\
\hline \multirow{5}{*}{$\begin{array}{l}\text { cv. Lvdie } \\
\text { (Green leaf) }\end{array}$} & $\mathrm{W}$ & $1.25 \pm 0.09 \mathrm{~b}$ & $0.28 \pm 0.03 \mathrm{~b}$ & $0.041 \pm 0.005 \mathrm{ab}$ & $0.0185 \pm 0.0023 \mathrm{a}$ \\
\hline & $\mathrm{RB}$ & $1.83 \pm 0.13 \mathrm{a}$ & $0.42 \pm 0.06 \mathrm{a}$ & $0.036 \pm 0.005 \mathrm{~b}$ & $0.0125 \pm 0.0017$ c \\
\hline & RBUV & $1.72 \pm 0.28 \mathrm{a}$ & $0.41 \pm 0.07 \mathrm{a}$ & $0.039 \pm 0.007 \mathrm{ab}$ & $0.0129 \pm 0.0021 \mathrm{c}$ \\
\hline & RBG & $1.47 \pm 0.14 \mathrm{~b}$ & $0.35 \pm 0.02 \mathrm{ab}$ & $0.046 \pm 0.004 \mathrm{a}$ & $0.0151 \pm 0.0014 \mathrm{~b}$ \\
\hline & RBFr & $1.38 \pm 0.18 b$ & $0.32 \pm 0.05 b$ & $0.045 \pm 0.005 \mathrm{a}$ & $0.0151 \pm 0.0017 \mathrm{~b}$ \\
\hline \multirow{5}{*}{$\begin{array}{c}\text { cv. Ziya } \\
\text { (Purple leaf) }\end{array}$} & $\mathrm{W}$ & $2.53 \pm 0.12 \mathrm{NS}$ & $0.52 \pm 0.03 \mathrm{a}$ & $0.022 \pm 0.001 \mathrm{~b}$ & $0.0099 \pm 0.0006 \mathrm{~b}$ \\
\hline & WR & $2.42 \pm 0.36 \mathrm{NS}$ & $0.44 \pm 0.06 \mathrm{~b}$ & $0.032 \pm 0.004 \mathrm{a}$ & $0.0117 \pm 0.0016 \mathrm{a}$ \\
\hline & $\mathrm{RB}$ & $2.24 \pm 0.12 \mathrm{NS}$ & $0.41 \pm 0.02 \mathrm{~b}$ & $0.036 \pm 0.002 \mathrm{a}$ & $0.0122 \pm 0.0006 \mathrm{a}$ \\
\hline & RBUV & $2.39 \pm 0.12 \mathrm{NS}$ & $0.45 \pm 0.02 \mathrm{~b}$ & $0.034 \pm 0.001 \mathrm{a}$ & $0.0114 \pm 0.0004 \mathrm{a}$ \\
\hline & RBG & $2.41 \pm 0.20 \mathrm{NS}$ & $0.46 \pm 0.05 b$ & $0.033 \pm 0.003 \mathrm{a}$ & $0.0111 \pm 0.0011 \mathrm{ab}$ \\
\hline
\end{tabular}

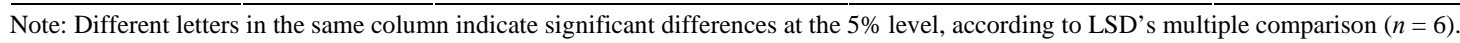




\section{Conclusions}

Growth, nutritional quality, and energy use efficiency of hydroponic lettuce could be strategically changed by supplemental selected lights in red plus blue LEDs or white LEDs. Moreover, lighting environment management for hydroponic lettuce production is also associated with different leaf color. Fresh weight, light and electrical energy use efficiencies of hydroponic lettuces grown under white plus red LEDs were higher or no significant differences compared with those grown under red plus blue LEDs. In conclusion, white plus red LEDs was suggested to substitute for red plus blue LEDs in hydroponic lettuce (cv. Lvdie and Ziya) production in plant factory with artificial lighting.

\section{Acknowledgements}

This work was supported by the National Key Research and Development Program of China (2017YFB0403901).

This manuscript was presented at 2019 International Symposium on Environment Control Technology for Value-added Plant Production hold in Beijing from Aug. 27-29, 2019.

\section{[References]}

[1] Yamori W. Photosynthesis and respiration. In: Kozai T, Niu G, Takagaki M (Ed.). Plant factory: An Indoor vertical farming system for effcient quality food production. Academic Press, 2016; pp. 141-148.

[2] Gupta S D, Agarwal A. Artificial lighting system for plant growth and development: Chronological advancement, working principles, and comparative assessment. In: Gupta S D (Ed.). Light emitting diodes for agriculture: Smart lighting. S Springer Nature Singapore Pte Ltd., 2017; pp. $1-24$.

[3] McCree K J. The action spectrum, absorptance, and quantum yield of photosynthesis in crop plants. Agricultural Meteorology, 1972; 9: 191-216.

[4] Caldwell C R, Britz S J. Effect of supplemental ultraviolet radiation on the carotenoid and chlorophyll composition of greenhouse-grown leaf lettuce (Lactuca sativa L.) cultivars. Journal of Food Composition and Analysis, 2006; 19: 637-644.

[5] Wang J, Lu W, Tong X Y, Yang Q C. Leaf morphology, photosynthetic performance, chlorophyll fluorescence, stomatal development of lettuce (Lactuca sativa L.) exposed to different ratios of red light to blue light. Frontiers in Plant Science, 2016; 7: 1-10.

[6] Peixe A, Ribeiro H, Ribeiro A, Soares M, Machado R, Rato A E, et al. Analysis of growth parameters for crop vegetables under broad and narrow LED spectra and fluorescent light tubes at different PPFs. Journal of Plant Studies, 2018; 7(1): 47-60.

[7] Yang X L, Xu H, Shao L, Li T L, Wang Y Z, Wang R. Response of photosynthetic capacity of tomato leaves to different LED light wavelength. Environmental and Experimental Botany, 2018; 150: 161-171.

[8] Naznin M T, Lefsrud M G, Gravel V, Wu B S, Reddy S. Effect of different ratios of red and blue LED light on lettuce production and phytochemical accumulation. ASHS Annual Conference, 2015; pp.4-7.

[9] Jeongwook H, Kang D H, Bang H S, Hong S G, Changhoo C, Kang K K. Early growth, pigmentation, protein content, and phenylalanine ammonia-lyase activity of red curled lettuces grown under different lighting conditions. Korean Journal of Horticultural Science and Technology, 2012; 30(1): 6-12.

[10] Son K, Oh M M. Leaf shape, growth, and antioxidant phenolic compounds of two lettuce cultivars grown under various combinations of blue and red light-emitting diodes. HortScience, 2013; 48(8): 988-995.

[11] Furuyama S, Ishigami Y, Hikosaka S, Goto E. Effects of blue/red ratio and light intensity on photomorphogenesis and photosynthesis of red leaf lettuce. Acta Horticulturae, 2014; 1037: 317-322.

[12] Pennisi G, Blasioli S, Cellini A, Maia L, Crepaldi A, Braschi I, et al. Unraveling the role of red:blue LED lights on resource use efficiency and nutritional properties of indoor grown sweet basil. Frontiers in Plant Science, 2019; 10: 1-14.

[13] Bian Z, Jiang N, Grundy S, Lu C. Uncovering LED light effects on plant growth: new angles and perspectives LED light for improving plant growth, nutrition and energy-use efficiency. Acta Horticulturae, 2018; 1227: 491-498.

[14] Agarwal A, Gupta S D, Barman M, Mitra A. Photosynthetic apparatus plays a central role in photosensitive physiological acclimations affecting spinach (Spinacia oleracea L.) growth in response to blue and red photon flux ratios. Environmental and Experimental Botany, 2018; 156: 170-182.

[15] Mitchell C A, Dzakovich M P, Gomez C, Lopez R, Burr J F, Hernández R, et al. Light-emitting diodes in horticulture. In: Janick $\mathrm{J}$ (Ed.). Horticultural Reviews. John Wiley \& Sons, Inc., 2015; pp. 6-8.

[16] Li Q, Kubota C. Effects of supplemental light quality on growth and phytochemicals of baby leaf lettuce. Environmental and Experimental Botany, 2009; 67(1): 59-64.

[17] Zhang X, He D X, Niu G, Yan Z N, Song J X. Effects of environment lighting on the growth, photosynthesis, and quality of hydroponic lettuce in a plant factory. Inter J Agric \& Biol Eng, 2018; 11(2): 33-40.

[18] He D X, Kozai T, Niu G, Zhang X. Light-emitting diodes for horticulture. In: Li J M, Zhang G Q (Ed.). Light-emitting diodes: Materials, processes, devices and applications. Springer International Publishing AG, 2019; pp. 521-547.

[19] Shen Y Z, Guo S S, Ai W D, Tang Y K. Effects of illuminants and illumination time on lettuce growth, yield and nutritional quality in a controlled environment. Life Sciences in Space Research, 2014; 2: 38-42.

[20] Chen X L, Xue X Z, Guo W Z, Wang L C, Qiao X J., Xue X Z. Growth and nutritional properties of lettuce affected by mixed irradiation of white and supplemental light provided by light-emitting diode. Scientia Horticulturae, 2016; 200: 111-118.

[21] Liu H, Fu Y M, Hu D W, Yu J, Liu H. Effect of green, yellow and purple radiation on biomass, photosynthesis, morphology and soluble sugar content of leafy lettuce via spectral wavebands "knock out". Scientia Horticulturae, 2018; 236: 10-17.

[22] Terashima I, Fujita T, Inoue T, Chow W S, Oguchi R. Green light drives leaf photosynthesis more efficiently than red light in strong white light: revisiting the enigmatic question of why leaves are green. Plant Cell Physiology, 2009; 50(4): 684-697.

[23] Kim H H, Goins G D, Wheeler R M, Sager J C. Green-light supplementation for enhanced lettuce growth under red- and blue-light-emitting diodes. HortScience, 2004; 39(7): 1617-1622.

[24] Kang W H, Park J S, Park K S, Son J E. Leaf photosynthetic rate, growth, and morphology of lettuce under different fractions of red, blue, and green light from light-emitting diodes (LEDs). Horticulture, Environment, and Biotechnology, 2016; 57(6): 573-579.

[25] Son K H, Oh M M. Growth, photosynthetic and antioxidant parameters of two lettuce cultivars as affected by red, green, and blue light-emitting diodes. Horticulture, Environment, and Biotechnology, 2015; 56(5): 639-653.

[26] Park Y, Runkle E S. Far-red radiation promotes growth of seedlings by increasing leaf expansion and whole-plant net assimilation. Environmental and Experimental Botany, 2017; 136: 41-49.

[27] Yan Z N, He D X, Niu G, Zhai H. Evaluation of growth and quality of hydroponic lettuce at harvest as affected by the light intensity, photoperiod and light quality at seedling stage. Scientia Horticulturae, 2019; 248: 138-144.

[28] Meng Q W, Runkle E S. Far-red radiation interacts with relative and absolute blue and red photon flux densities to regulate growth, morphology, and pigmentation of lettuce and basil seedlings. Scientia Horticulturae, 2019; 255: 269-280.

[29] Stutte G W, Edney S, Skerritt T. Photoreguation of bioprotectant content of red leaf lettuce with light-emitting diodes. HortScience, 2009; 44(1): 79-82.

[30] Lee M, Son J E, Oh M. Growth and phenolic content of sowthistle grown in a closed-type plant production system with a UV-A or UV-B lamp. Horticulture, Environment, and Biotechnology, 2013; 54(6): 492-500.

[31] Shimizu H. Effect of light quality on secondary metabolite production in leafy greens and seedling. In: Kozai T, Fujiwara K, Runkle E S (Ed.). LED lighting for urban agriculture. Springer Nature Singapore Pte Ltd., 2016; pp. 239-260.

[32] Tsormpatsidis E, Henbest R G C, Battey N H, Hadley P. The influence of ultraviolet radiation on growth, photosynthesis and phenolic levels of green and red lettuce: Potential for exploiting effects of ultraviolet radiation in a production system. Annals of Applied Biology, 2010; 156: 357-366.

[33] Park J E, Park Y G, Jeong B R, Hwang S J. Growth and anthocyanin 
content of lettuce as affected by artificial light source and photoperiod in a closed type plant production system. Korean Journal of Horticultural Science and Technology, 2012; 30(6): 673-679.

[34] Yan Z N, He D X, Niu G, Zhou Q, Qu Y H. Growth, nutritional quality, and energy use efficiency of hydroponic lettuce as influenced by daily light integrals exposed to white versus white plus red LEDs. HortScience, 2019, 54(10): 1737-1744.

[35] Arnon D I. Copper enzymes in isolated chloroplasts. Polyphenoloxidase in Beta vulgaris. Plant Physiology, 1949; 24: 1-15.

[36] Li H S. Experimental principle and technology of plant physiology and biochemistry. Higher Education Press, 2000; pp. 123-124.

[37] Cataldo D A, Maroon M, Schrader L E, Youngs V L. Rapid colorimetric determination of nitrate in plant tissue by nitration of salicylic acid. Communications in Soil Science and Plant Analysis, 1975; 6(1): 71-80.

[38] Cao J K, Jiang W B, Zhao Y M. Physiological and biochemical experimental guidance of fruits and vegetables. China Light Industry Press Ltd., 2007; pp. 49-50.

[39] Kozai T, Niu G. Plant factory as a resource-efficient closed plant production system. In: Kozai T, Niu G, Takagaki M (Ed.). Plant factory: An indoor vertical farming system for efficient quality food production. Academic Press, 2016; pp. 77-78.

[40] Kim H H, Wheeler R M, Sager J C, Goins G D. A comparison of growth and photosynthetic characteristics of lettuce grown under red and blue light-emitting diodes (LEDs) with and without supplemental green LEDs. Acta Horticulturae, 2004; 659: 467-475.

[41] Mickens M A, Skoog E J, Reese L E, Barnwell P L, Spencer L E, Massa G $\mathrm{D}$, et al. A strategic approach for investigating light recipes for
'Outredgeous' red romaine lettuce using white and monochromatic LEDs. Life Sciences in Space Research, 2018; 19: 53-62.

[42] Lee J W, Kang W H, Park K S, Son J E. Spectral dependence of electrical energy-based photosynthetic efficiency at single leaf and canopy levels in green- and red-leaf lettuces. Horticulture, Environment, and Biotechnology, 2017; 58(2): 111-118.

[43] Paradiso R, Meinen E, Snel J F H, Visser P D, Ieperen W V, Hogewoning $\mathrm{S} \mathrm{W}$, et al. Spectral dependence of photosynthesis and light absorptance in single leaves and canopy in rose. Scientia Horticulturae, 2011; 127, 548-554.

[44] Lee M J, Park S Y, Oh M M. Growth and cell division of lettuce plants under various ratios of red to far-red light-emitting diodes. Horticulture, Environment, and Biotechnology, 2015; 56(2): 186-194.

[45] Yang Z, He W, Mou S, Wang X, Chen D, Hu X, et al. Plant growth and development of pepper seedlings under different photoperiods and photon flux ratios of red and blue LEDs. Transactions of the CSAE, 2017; 33(17): 173-180. (in Chinese)

[46] Han T, Vaganov V, Cao S X, Li Q, Ling L L, Cheng X Y, et al Improving "color rendering" of LED lighting for the growth of lettuce. Scientific Reports, 2017; 7: 1-7.

[47] Meng Q W, Kelly N, Runkle E S. Substituting green or far-red radiation for blue radiation induces shade avoidance and promotes growth in lettuce and kale. Environmental and Experimental Botany, 2019; 162: 383-391.

[48] Samuoliene G, Brazaityte A, Sirtautas R, Virsile A, Sakalauskaite J, Sakalauskiene S, et al. LED illumination affects bioactive compounds in romaine baby leaf lettuce. Journal of the Science of Food and Agriculture, 2013; 93: 3286-3291. 